\title{
Desalojos forzosos en Chile con miras al Derecho Internacional de Derechos Humanos
}

\author{
Tatiana Torres Montenegro*
}

\begin{abstract}
RESUMEN
De la política habitacional chilena se pueden desprender variadas consecuencias, una de ellas es la cantidad de población que habita hoy en asentamientos irregulares o precarios y que son objeto de desalojos forzosos por parte de particulares o del Estado. Este trabajo pretende indicar cuáles son los parámetros internacionales respecto de los desalojos forzosos y analizar la normativa existente en Chile que los regula. De esta manera, permitirá un análisis más exhaustivo al momento de encontrarnos frente a una situación de desalojo, y que sirva de apoyo a aquellos que intenten recursos de protección en orden a detener dichas órdenes.
\end{abstract}

Desalojo forzoso - derecho internacional de los Derechos Humanos - desahucio

\section{Forced evictions in Chile in relation with International Human Rights Law}

\begin{abstract}
Several consequences can be derived from the Chilean housing policy, one of which is the number of people who live in irregular or precarious settlements today, and who are subject to forced evictions by individuals or the State. This work aims to indicate what are the international parameters regarding forced evictions and analyze the existing regulations in Chile that regulate them. In this way, can allow a more exhaustive analysis when faced with an eviction situation, and that will serve as a support to those who seek protection resources in order to stop such orders
\end{abstract}

Forced eviction - international Human Rights law - eviction

* Licenciada en Ciencias Jurídicas y Sociales, Universidad de Concepción. Correo electrónico: tatitorresmontenegro@gmail.com.

Artículo recibido el 2 de abril de 2018 y aceptado para su publicación en este número el 18 de enero de 2019. 


\section{INTRODUCCIÓN}

C omo resultado de una política habitacional general con falta de enfoque de derechos humanos, en Chile es posible apreciar la existencia de numerosas familias que viven actualmente en asentamientos informales, con falta de acceso a servicios básicos, en donde los elementos integradores del derecho a la vivienda adecuada no se visualizan y la expresión de vivir en dignidad, seguridad y paz en alguna parte, parece un rezo ajeno a toda realidad.

De conformidad con lo indicado por la Organización de las Naciones Unidas, se entiende por asentamientos informales un grupo de más de 10 viviendas en terrenos públicos o privados, construidos sin permiso del dueño, sin ninguna formalidad legal y sin cumplir con las leyes de planificación urbana ${ }^{1}$. Lo que caracteriza a este tipo de asentamiento es su precariedad en los servicios, falta de habitabilidad y de seguridad jurídica de la tenencia.

Pero además estamos frente a una situación en la actualidad en la que incluso personas a las que les fuera otorgado en dominio viviendas para que autoagenciaran su vida, han sido desprovistas de ellas producto de los remates, lo que ha sido observado por la Relatora especial para la vivienda adecuada ${ }^{2}$ doña Raquel Rolnik, indicando que "El paradigma que consideraba la propiedad de la vivienda como la forma de tenencia más segura ha resultado ser falso, dado que uno de los principales resultados de las crisis recientes ha sido el aumento de las ejecuciones hipotecarias" ${ }^{\text {. }}$.

Si bien puede considerarse suficientemente grave el hecho que por distintas razones existan 40.541 familias en el $2017^{4}$ viviendo en condiciones que atentan no tan solo contra el derecho a la vivienda adecuada, sino que también, en virtud del principio de interdependencia de los derechos humanos, atentan contra el derecho a la vida, la integridad física y psíquica, la alimentación adecuada, el trabajo, la salud, entre otros; nos encontramos con otra situación igualmente preocupante asociada a esta forma de vida, y que tiene que ver con los desalojos.

${ }^{1}$ Hábitat Worldmap, 2017.

2 "Un relator especial es un experto independiente designado por el Consejo de Derechos Humanos para examinar la situación de un país o un asunto concreto de derechos humanos, e informar al respecto. Ejerce el cargo a título honorario y no forma parte del personal de las Naciones Unidas ni percibe un sueldo por el desempeño de su mandato. Los relatores especiales forman parte de los procedimientos especiales del Consejo de Derechos Humanos".

${ }^{3}$ Consejo de Derechos Humanos, 2012, p. 11.

${ }^{4}$ Techo, 2017. 


\section{Consideraciones previas en Cuanto a la Aplicación del derecho INTERNACIONAL DE LOS DERECHOS HUMANOS AL DERECHO INTERNO}

Este tema ha sido objeto de análisis profundo por parte de la doctrina nacional, y por motivos de extensión de este trabajo solo indicaremos que existe consenso que los tratados internacionales respecto de derechos humanos se aplican al derecho interno.

En virtud de la norma del artículo $5^{\circ}$ de la Constitución Política de la República que indica que "El ejercicio de la soberanía reconoce como limitación el respeto a los derechos esenciales que emanan de la naturaleza humana. Es deber de los órganos del Estado respetar y promover tales derechos, garantizados por esta Constitución, así como por los tratados internacionales ratificados por Chile y que se encuentren vigentes", se entiende que una vez que los tratados acerca de derechos humanos han cumplido con los trámites legislativos establecidos en la Constitución, estos son aplicables al derecho interno y los derechos contenidos en ellos constituyen una limitación al ejercicio de la soberanía.

La discusión radica en torno a la jerarquía normativa que dichos tratados tienen en la estructura legal del país, para algunos (entre ellos Claudio Nash ${ }^{5}$ ) tendrían rango constitucional; para otros (entre ellos Bertelsen ${ }^{6}$ ) las normas internacionales serían de rango infraconstitucional, siendo la posición mayoritaria en los tribunales de justicia la de dar mayor prevalencia a las normas constitucionales internas que a los tratados internacionales sobre derechos humanos. Lo anterior tiene relevancia para efectos de su aplicación práctica y exigibilidad en los tribunales.

Resulta útil para efectos de determinar la aplicación de estándares internacionales en el derecho interno, tener en consideración la construcción doctrinal del bloque constitucional de derechos fundamentales, que se entiende como

"el conjunto de derechos de la persona (atributos) asegurados por fuente constitucional o por fuentes del derecho internacional de los derechos humanos (tanto el derecho convencional como el derecho consuetudinario y los principios de ius cogens) y los derechos implícitos, expresamente incorporados a nuestro ordenamiento jurídico por vía del artículo 29 literal c) de la Convención Americana de Derechos Humanos, todos los cuales, en el ordenamiento constitucional chileno, constituyen límites a la soberanía, como lo especifica categóricamente el artículo $5^{\circ}$ inciso segundo de la Constitución chilena vigente" 7 .

Así, a base del referido bloque las normas sobre derechos fundamentales deben ser interpretadas armónicamente con las respectivas fuentes normativas de derecho interno como las fuentes convencionales internacionales, con las claves hermenéuticas del Derecho

\footnotetext{
5 NASH, 2012.

${ }^{6}$ Bertelsen, 1996.

${ }^{7}$ Nogueira, 2009, p. 149.
} 
de los Derechos Humanos y sus órganos de aplicación (como por ejemplo el Comité de Derechos Económicos, Sociales y Culturales) ${ }^{8}$.

En este contexto existen distintas posiciones respecto de reconocer como fuente del derecho internacional al denominado soft law, como fuente distinta a las contenidas en el artículo 38.1 del Estatuto de la Corte Internacional de Justicia. Se ha indicado que el soft law está compuesto por un conjunto de decisiones de los Estados o de organizaciones internacionales cuyo carácter no es jurídicamente vinculante respecto de los Estados 9 . También, se ha señalado, que este término busca describir la existencia de fenómenos jurídicos caracterizados por carecer de fuerza vinculante aunque no carentes de efectos jurídicos o al menos con cierta relevancia jurídica ${ }^{10}$.

De conformidad con la mayoría de la doctrina, la utilidad del soft law es aceptada por cuanto permitiría avanzar en el sistema de protección de derechos humanos mediante la determinación progresiva de estándares más avanzados. No obstante lo anterior, otro sector de la doctrina estima lo contrario, que la extrema elasticidad de las normas de soft law no hace sino incrementar el poder de las instituciones internacionales como las Cortes y los comités especializados, los que impondrían sus decisiones a Estados que, por ejemplo, no formaron parte de la causa específica sujeta al conocimiento del tribunal ${ }^{11}$.

Para efectos de este trabajo, entendemos que las normas del soft law constituyen una herramienta para interpretar el derecho a la vivienda adecuada, y que por tanto sirven de Carta Gantt para los Estados al momento de cumplir con su obligación de promover, proteger, respetar y consagrar los derechos humanos consagrados en los tratados internacionales vigentes.

\section{DeRECho A LA VIVIENDA ADECUADA}

El derecho a la vivienda adecuada se entiende como aquel gracias a que se puede vivir en dignidad, paz y seguridad en algún lugar ${ }^{12}$, de conformidad a lo indicado en la observación general No 4 del Comité de Derechos Sociales, Económicos y Culturales, en adelante el Comité. Se considera además como parte del derecho a un nivel de vida adecuado, de acuerdo con lo establecido en el numeral 11 del Pacto Internacional sobre Derechos Económicos, Sociales y Culturales, en adelante el Pacto, y en el artículo 25 de la Declaración Universal de las Naciones Unidas.

En Chile se ha entendido por parte de la Administración Pública como el bien material que brinda cobijo a las personas ${ }^{13}$, atendiendo a su funcionalidad y composición física, en contraposición al valor que presta al ser humano. Así se puede desprender de

\footnotetext{
${ }^{8}$ Nogueira, 2009, p. 150.

${ }^{9}$ Candia, 2016, p. 39.

${ }^{10}$ Del Toro, 2006, p. 519.

${ }^{11}$ D'ASPREMONT, 2011, p. 134.

12 Consejo de Derechos Económicos, Sociales y Culturales, 1991, p. 2.

${ }^{13}$ INDH, 2012, p. 253.
} 
la definición otorgada por la Ordenanza General de Urbanismo y Construcciones que indica en su artículo 1.1.2 que la vivienda es la edificación o unidad destinada al uso habitacional ${ }^{14}$.

También se ha definido como el espacio construido donde un grupo familiar puede concretar la vida de interrelación de sus miembros, así como el desarrollo de las actividades personales de cada uno de ellos sin conflictos respecto de las pautas de comportamiento propias de su cultura. Debe además tener la capacidad de insertarse y vincularse satisfactoriamente a un contexto ambiental que responda tanto a requerimientos objetivos de salubridad, accesibilidad y servicios urbanos como a los requerimientos valorativos culturales que hagan posible a la familia participar de un grupo o comunidad $^{15}$.

Es en el contexto de la vivienda donde se satisfacen múltiples necesidades humanas, psicológicamente satisface necesidades de privacidad y espacio personal, físicamente protege del ambiente y del clima, y socialmente constituye un punto de reunión esencial en el que se forjan y nutren importantes relaciones interpersonales ${ }^{16}$.

Diversos cuerpos normativos han regulado la adquisición de viviendas por parte de familias vulnerables o de sectores medios, financiadas con subsidios habitacionales otorgados por única vez por el Estado. Tanto la adquisición como construcción de la vivienda objeto de los programas habitacionales tienen como base la definición otorgada por la Ordenanza General de Urbanismo y Construcciones, siendo relevante las características constructivas y las condiciones de habitabilidad, que han ido variando a lo largo del desarrollo de la política habitacional chilena. Hoy es posible abstraer de esta última que se tiene como prioridad disminuir tanto el déficit cuantitativo como el cualitativo de vivienda, mejorar la ubicación y localización de la misma, propender a la integración social y territorial, realizar acciones afirmativas respecto de población especialmente vulnerable, como las mujeres, adultos mayores, migrantes y niños, niñas y adolescentes, entre otras.

Por lo anterior, para configurar el derecho a la vivienda desde el punto de vista meramente legal chileno, entenderemos que se refiere al acceso a la edificación que sirve de refugio y habitación a personas, con características de habitabilidad aptas para el desarrollo de la vida diaria en condiciones de salud e higiene, localizadas en proximidad de centros de salud y escuelas (las viviendas urbanas), y que recoge las características propias culturales de cada grupo o familia.

Sin perjuicio de lo referido, lo efectivo es que el derecho a la vivienda adecuada, tal cual lo plantean los organismos internacionales, no tiene consagración constitucional en nuestro país. Esto último ha sido objeto de observaciones por parte de la relatora especial para el derecho a la vivienda adecuada, mas no se condice con la situación que es posible observar en otros países latinoamericanos.

\footnotetext{
${ }^{14}$ Decreto Supremo No $47,1992$.

${ }^{15}$ De Los Ríos, 2008, p. 130.

16 Nash y Paredes; 2011, p. 204.
} 
Así tenemos el caso de Colombia, que contempla el derecho a una vivienda digna en su texto constitucional en el artículo $51^{17}$, el que tiene un carácter de asistencial que requiere un desarrollo legal previo y que debe ser prestado directamente por la administración, no otorgando a la persona un derecho subjetivo de exigir en forma inmediata del Estado su plena satisfacción, pues requiere de condiciones jurídico-materiales que lo hagan posible ${ }^{18}$.

Por su parte, Argentina consagra el derecho a una vivienda digna en el artículo 14 bis ${ }^{19}$ de la Constitución Nacional, configurándolo como la disposición de un espacio físico adecuado, constituyendo un derecho humano fundamental, y que conlleva un deber de parte de las autoridades públicas de garantizar un nivel mínimo de efectiva vigencia, al menos en un estadio básico ${ }^{20}$.

Desde el punto de vista internacional entendemos que para configurar el derecho a la vivienda debemos estar frente a determinados elementos que han sido identificados por el Comité en su observación general $\mathrm{N}^{\circ} 4$, y que $\operatorname{son}^{21}$ :

1. Seguridad jurídica de la tenencia, al que nos referiremos más adelante.

2. Disponibilidad de servicios, materiales, facilidades e infraestructuras; una vivienda adecuada debe contener ciertos servicios indispensables para la salud, la seguridad, la comodidad y la nutrición.

3. Gastos soportables, los gastos personales o del hogar que entraña la vivienda deberían ser de un nivel que no impidiera ni comprometiera el logro y la satisfacción de otras necesidades básicas.

4. Habitabilidad, en sentido de poder ofrecer espacio adecuado a sus ocupantes y de protegerlos del frío, la humedad, el calor, la lluvia, el viento u otras amenazas para la salud, de riesgos estructurales y de vectores de enfermedad.

5. Asequibilidad, la vivienda adecuada debe ser asequible a los que tengan derecho. Debe concederse a los grupos en situación de desventaja un acceso pleno y sostenible a los recursos adecuados para conseguir una vivienda.

6. Lugar, que permita el acceso a las opciones de empleo, los servicios de atención de la salud, centros de atención para niños, escuelas y otros servicios sociales.

17 Artículo 51 Constitución Política de Colombia: Todos los colombianos tienen derecho a vivienda digna. El Estado fijará las condiciones necesarias para hacer efectivo este derecho y promoverá planes de vivienda de interés social, sistemas adecuados de financiación a largo plazo y formas asociativas de ejecución de estos programas de vivienda”.

18 Olano, 2006, p. 111.

${ }^{19}$ Artículo 14 bis Constitución Nacional de la República Argentina: El Estado otorgará los beneficios de la seguridad que tendrá carácter de integral e irrenunciable. En especial, la ley establecerá [...] la protección integral de la familia; la defensa del bien de familia; la compensación económica familiar y el acceso a una vivienda digna.

${ }^{20}$ Augusto, p. 254.

${ }^{21}$ Comité de Derechos Económicos, Sociales y Culturales, 1991, p. 3. 
7. Adecuación cultural, la manera en que se construye la vivienda, los materiales de construcción utilizados y las políticas en que se apoyan deben permitir adecuadamente la expresión de la identidad cultural y la diversidad de la vivienda.

\section{Desalojos a la luz del Derecho Internacional de los Derechos Humanos}

Dentro de los elementos que constituyen el derecho a la vivienda adecuada mencionados anteriormente, nos encontramos con la seguridad jurídica de la tenencia, respecto de ella el Comité señala que "Sea cual fuere el tipo de tenencia, todas las personas deben gozar de cierto grado de seguridad de tenencia que les garantice una protección legal contra el desahucio, el hostigamiento u otras amenazas" 22 . Por lo anterior, aparece como primer cuestionamiento a qué se refiere el Comité cuando habla de desahucio.

Como una primera aproximación es del caso señalar que la palabra desahuciar es una palabra compuesta por el prefijo des-, que proviene del latino dis- y que indica inversión de una acción, y del arcaico verbo afuciar, formado con a-, del latín ad-, y el verbo latino fiduciare que significa dar confianza, avalar o garantizar. Desahuciar es pues quitar toda confianza, igual si lo aplicamos a despedir a un arrendatario (se retira la confianza que en él se tenía y se produce el desahucio). ${ }^{23}$

Por otra parte, entendemos desahucio de conformidad con lo que indica el Diccionario de la Real Academia Española, como la "acción y efecto de desahuciar" ${ }^{24}$, la que a su vez es definida en su tercera acepción como "Dicho de un dueño o de un arrendador: Despedir al inquilino o arrendatario mediante un acción legal" 25 . En virtud de lo anterior podemos entender que el término utilizado por el Comité se refiere al significado referente a una propiedad, en cuanto corresponde a un término legal. No obstante, el Comité en sus posteriores observaciones ha utilizado como sinónimo de desahucio el término desalojo, que es menos técnico y al que nos referiremos a continuación.

La palabra desalojar, proviene de des (ya explicado) y alojar, por su parte alojar proviene del germánico launja, enramado por medio del provenzal antiguo alotjar, y que significa hospedar o aposentar ${ }^{26}$, por lo que desalojar significaría quitar o expulsar a quien se hospeda, o sacar o hacer salir de un lugar a una persona o cosa.

El mencionado diccionario expresa como significado de desalojo, la "acción de desalojar" 27 , siendo esta última en su primera acepción, "sacar o hacer salir de un lugar a alguien o algo" 28 , y en su cuarta acepción como "dejar el hospedaje, sitio o morada

\footnotetext{
22 Comité de Derechos Económicos, Sociales y Culturales, 1991, p. 3.

${ }^{23}$ Etimologías de Chile, 2018.

${ }^{24}$ Diccionario de la Real Academia Española, 2018.

25 Ídem.

${ }^{26}$ Diccionario de la Real Academia Española, 1992.

${ }^{27}$ Ídem.

${ }^{28}$ Ídem.
} 
voluntariamente”. De esta manera, por sí solo, el concepto no tiene una connotación negativa que pudiese llevarnos a pensar en su prohibición, o que constituya en sí mismo una violación a los derechos humanos. Lo que hace la diferencia radica en el adjetivo forzoso, el que cambia el sentido de la palabra, dándole una connotación obligatoria, contra voluntad o ineludible, e incluso violenta.

En cuanto a qué entendemos por hostigamiento, este es la acción y efecto de hostigar, que significa "incitar con insistencia a alguien para que haga algo" 29 , de esta manera es posible que una persona sea objeto de injerencias en la vida diaria producto del no pago de una deuda hipotecaria, o bien por estar viviendo en un terreno que no le pertenece, lo que genera efectos psicológicos adversos, en especial si dicha insistencia está acompañada de violencia.

Lo expresado nos permite comprender de mejor forma la definición entregada por el Comité en su observación general $N^{0} 7$ respecto del desalojo forzoso, según este, es "el hecho de hacer salir a personas, familias y/o comunidades de los hogares y/o las tierras que ocupan en forma permanente o provisional, sin ofrecerles medios apropiados de protección legal o de otro índole ni permitirles su acceso a ellos" ${ }^{30}$. El Comité señala además que "considera que las instancias de desahucios forzados son prima facie incompatibles con los requisitos del Pacto y solo podrían justificarse en las circunstancias más excepcionales y de conformidad con los principios pertinentes del derecho internacional" 31 .

Se ha señalado por parte de la Subcomisión de Promoción y Protección de los Derechos Humanos, reiterando la idea señalada por la Comisión de Derechos Humanos en la resolución 1993/77,

“que la práctica del desalojo forzoso constituye una violación grave de un amplio conjunto de derechos humanos, en particular del derecho a una vivienda adecuada, a conservar la vivienda, a la libertad de circulación, a la vida privada, a la propiedad, a un nivel de vida adecuado, a la seguridad de la vivienda, a la seguridad de la persona, a la seguridad de tenencia de la vivienda y a la igualdad de trato. [...] Recomienda también a todos los gobiernos que velen por que todo desalojo que se considere legal se lleve a cabo de manera tal que no viole ninguno de los derechos humanos de las personas desalojadas" 32 .

Podemos apreciar, por tanto, que aquellos desalojos que se efectúen de conformidad con las disposiciones de los pactos internacionales sobre derechos humanos no se encuentran prohibidos por el derecho internacional, por lo que los Estados deben tener en consideración los estándares, y aplicarlos en cada procedimiento que se haga necesario ejecutar frente a una ocupación irregular de un inmueble; pudiendo desprenderse del

\footnotetext{
29 Diccionario de la Real Academia Española, 2018.

30 Comité de Derechos Económicos, Sociales y Culturales, 1997, p. 1.

31 Comité de Derechos Económicos, Sociales y Culturales, 1991, p. 6.

32 Subcomisión de Promoción y Protección de los Derechos Humanos, 2003, p. 2.
} 
carácter de prohibición, que el Estado puede proceder o permitir los desalojos solo de manera excepcional. En conclusión, todo aquel procedimiento que no cumpla con lo antes dicho, se encuentra prohibido y constituye una violación a los derechos humanos, siguiendo el razonamiento de lo expresado en los párrafos anteriores.

En cuanto al fundamento legal de la prohibición a los desalojos forzosos, según lo indicado por el propio Comité, se encuentra en el párrafo $1^{\circ}$ del artículo 11 del Pacto donde se dispone que

"Los Estados Partes en el presente Pacto reconocen el derecho de toda persona a un nivel de vida adecuado para sí y su familia, incluso alimentación, vestido y vivienda adecuados, y a una mejora continua de las condiciones de existencia" ${ }^{33}$.

Esto en relación con el artículo 17 párrafo $1^{\circ}$ del Pacto Internacional de Derechos Civiles y Políticos (similar a la contenida en la Convención Americana sobre Derechos Humanos, en su artículo 11 párrafo $2^{\circ 34}$ ), que indica que "Nadie será objeto de injerencias arbitrarias o ilegales en su vida privada, su familia, su domicilio o su correspondencia, ni de ataques ilegales a su honra y reputación"35.

A propósito, podemos encontrar lo dispuesto por el Comité de Derechos Humanos respecto del artículo 17 ya citado conociendo de una denuncia por violación al Pacto Internacional de Derechos Civiles y Políticos, el que indica:

A este respecto, el Comité recuerda que el término "domicilio", empleado en el artículo 17 del Pacto, debe entenderse en su acepción de lugar donde una persona reside o ejerce su ocupación habitual [el subrayado es nuestro]. En la presente comunicación, es indiscutible que la comunidad de Dobri Jeliazkov, donde están ubicados los domicilios de los autores y donde han residido ininterrumpidamente, ha existido desde hace más de 70 años con la aquiescencia de las autoridades del Estado parte, y que el domicilio de los autores figura en los registros de la policía. En estas circunstancias, el Comité considera que las viviendas de los autores en la comunidad de Dobri Jeliazkov son sus “domicilios” en el sentido del artículo 17 del Pacto, independientemente del hecho de que los autores no sean los propietarios $\underline{\text { legítimos de la parcela de tierra en que se construyeron esas viviendas }}{ }^{36}$.

Como corolario, el derecho a la vivienda adecuada conlleva en uno de sus elementos integradores la prohibición de los desalojos forzosos por cuanto estos atentan contra la seguridad jurídica de la tenencia, y al mismo tiempo afectan la vida privada de la persona,

\footnotetext{
33 Pacto Internacional de Derechos Económicos, Sociales y Culturales, 1976.

${ }^{34}$ Nadie puede ser objeto de injerencias arbitrarias o abusivas en su vida privada, en la de su familia, en su domicilio o en su correspondencia, ni de ataques ilegales a su honra o reputación. Artículo 11 párrafo 2 Convención Americana sobre Derechos Humanos.

35 Pacto Internacional de Derechos Civiles y Políticos, 1976.

${ }^{36}$ Comité de Derechos Humanos, 2012, p. 14.
} 
su familia y su domicilio, constituyendo una violación a los derechos humanos, en la medida que dichos desalojos no cumplan con los estándares internacionales.

Respecto de la importancia de cumplir con los estándares internacionales, el Comité, quien conociendo de una denuncia presentada contra España por un proceso de desalojo ordenado en virtud de un proceso ejecutivo de cobro de crédito hipotecario, ha indicado entre sus recomendaciones que España debe:

“Adoptar medidas legislativas pertinentes para garantizar que el procedimiento de ejecución hipotecaria y las normas procesales establezcan requisitos [...] y procedimientos adecuados a seguir antes de que se proceda a una subasta de una vivienda o a un desalojo, en observancia del Pacto y tomando en cuenta la observación general núm. 7 del Comité”37.

En consecuencia, en virtud de la obligación legal que tienen los Estados establecida en el artículo $2^{\circ}$ del Pacto de utilizar todos los medios apropiados para promover el derecho a la vivienda adecuada, y por ende prohibir el desalojo forzoso efectuado en los términos ya relatados, es que se hace necesario adaptar la legislación nacional, tomando las siguientes medidas:

a. "Que brinden la máxima seguridad de la tenencia posible a los ocupantes de las viviendas y tierras,

b. Se ajusten al Pacto

c. Regulen estrictamente las circunstancias en que se pueden llevar a cabo los desalojos" 38 .

Se debe tener en especial consideración la relación que existe entre los desalojos forzosos y la discriminación a grupos vulnerables, pues es de toda notoriedad que quienes se ven expuestos a estos procedimientos son personas en situación de grave vulnerabilidad social o de escasos recursos, que además son mujeres jefas de hogar, niños, niñas y adolescentes en edad escolar, migrantes, adultos mayores y personas en situación de discapacidad. En este sentido se ha razonado que "la pobreza es tanto una causa como una consecuencia de los desalojos. Por un lado la falta de opciones y de seguridad de la tenencia y la imposibilidad de acceder a la vivienda pueden obligar a los pobres a vivir en asentamientos informales y con el temor de ser desalojados. Por otro, los hechos demuestran que los desalojos forzosos suelen dar lugar a un mayor empobrecimiento o indigencia"39.

Lo dicho parece demostrar la existencia de un círculo perverso, en donde las personas se ven obligadas por la realidad a asentarse irregularmente, en virtud de la necesidad

\footnotetext{
37 Comité de Derechos Económicos, Sociales y Culturales, 2015, p. 17.

38 Comité de Derechos Económicos, Sociales y Culturales, 1997, p. 3.

39 Oficina del Alto Comisionado de Derechos Humanos, 2014, p. 27.
} 
propia de un hogar, y respecto del cual carecen de toda seguridad jurídica de la tenencia entre otros elementos, exponiéndose a múltiples vulneraciones de derechos, culminando el proceso con un desalojo forzoso que los obliga a sumirse en una pobreza aún mayor. Siguiendo la misma línea, "El Comité también ha reconocido las devastadoras consecuencias del desalojo de familias y comunidades y ha establecido que no debería permitirse si va a dar lugar a una falta de hogar" ${ }^{40}$.

\section{Desalojos legales a la luz del Derecho Internacional}

Respecto de los desalojos legales permitidos en situaciones excepcionales, se ha sugerido por el Relator para la Vivienda Adecuada don Miloon Kothari, en su informe $\mathrm{A} / \mathrm{HRC} / 4 / 18$, que se deben cumplir ciertos requisitos, cuales son:

a. "Estar autorizados por la ley;

b. Llevarse a cabo de acuerdo con el derecho internacional relativo a los derechos humanos;

c. Hacerse únicamente con el fin de promover el bienestar general;

d. Ser razonable y proporcional;

e. Estar reglamentado de tal forma que se garantice una indemnización y rehabilitación completas y justas; y

f. Realizarse de acuerdo con las directrices sobre los desalojos y el desplazamiento generados por el desarrollo, anexo de Informe A/HRC/4/18"41.

Respecto de estar autorizados por la ley, se ha indicado que

"una resolución administrativa o judicial por sí sola no se traduce necesariamente en un desalojo legal o justificado. Incluso si un tribunal nacional ha fallado a favor de un desalojo o si el desalojo se lleva a cabo de conformidad con la legislación nacional, la situación todavía puede constituir un desalojo forzoso si no cumple con las normas internacionales de derechos humanos y las obligaciones del Estado al respecto" 42 .

De conformidad con los lineamientos que ha entregado el Comité deben considerarse ciertas garantías en el evento que sea del todo necesario practicar un desalojo, y que están contenidas en la Observación General $N^{0} 7$, las que son ${ }^{43}$ : consulta a los afectados, plazo razonable de notificación a los mismos, información respecto del proceso de desalojo,

\footnotetext{
40 Consejo de derechos humanos, 2016, p. 15.

41 Ob. cit., pp. 6-7.

42 Oficina del Alto Comisionado de Derechos Humanos, 2014, p. 5.

43 Comité de Derechos Económicos, Sociales y Culturales, 1997, p. 4.
} 
presencia de funcionarios públicos, identificación de personas que efectúan el desalojo, no realizarlos en la noche o de mal tiempo, ofrecer asistencia jurídica y recursos judiciales.

Indica además el Comité que "cuando los afectados por el desalojo no dispongan de recursos, el Estado Parte deberá adoptar todas las medidas necesarias, en la mayor medida que permitan sus recursos, para que se proporcione otra vivienda, reasentamiento o acceso a tierras productivas, según proceda" ${ }^{4}$.

Por tanto, vemos que es posible realizar desalojos en la medida que se cumpla con los estándares internacionales del Derecho internacional de los derechos humanos, y para actuar en dicho procedimiento podemos distinguir actuaciones que se deben cumplir en distintas etapas: en forma previa al desalojo, durante y con posterioridad.

En forma previa al desalojo, lo principal está centrado en la participación de los afectados por el mismo, debiendo incluirse avisos a todos quienes pudieran verse afectados, difusión, plazo razonable para la formulación de observaciones, facilitar asesoramiento jurídico y audiencias públicas para impugnar la decisión de desalojo ${ }^{45}$ :

Durante el desalojo deben asistir obligatoriamente funcionarios gubernamentales o representantes en su lugar, quienes deben estar debidamente identificados y presentar una autorización oficial para proceder al mismo ${ }^{46}$. Es importante que el uso de la fuerza legal respete los principios de la necesidad y la proporcionalidad y que no se realicen de noche o durante las fiestas de una determinada comunidad.

Es posible desprender la necesidad de que exista una justificación para proceder al desalojo, la que debe ser comunicada a los afectados. Así también lo ha entendido la Corte Europea de Derechos Humanos en el caso denominado "Connors v. Reino Unido", el que al resolver respecto de un desalojo realizado a una comunidad de gitanos indicó que:

"En conclusión, el Tribunal considera que el desalojo del solicitante y a su familia del sitio de la autoridad local no cumplió con el requisito de garantías procesales, a saber, el requisito de establecer una justificación de la grave injerencia en sus derechos y, en consecuencia, no puede considerarse justificado por una 'necesidad social apremiante' o proporcional al objetivo legítimo que se persigue" 47 .

Con posterioridad al desalojo se ha señalado como lineamiento que el gobierno debe proporcionar una indemnización justa y un alojamiento alternativo suficiente, además de asegurar el acceso a alojamiento básico y vivienda, vestimenta y alimentos esenciales, servicios médicos, y educación para los niños ${ }^{48}$ :

Teniendo claro el marco internacional dentro del que se puede actuar tratándose de desalojos, y cómo este cuando es forzoso se encuentra proscrito por el derecho internacional, procederemos a analizar la situación normativa actual en Chile.

\footnotetext{
${ }^{44}$ Ob. cit., p. 4.

45 Consejo de Derechos Humanos I, 2007, pp. 9-10.

${ }^{46}$ Ob. cit., p. 11.

47 Corte Europea de Derechos Humanos, 27.05. 2004, Caso “Connors versus Reino Unido”.

48 Consejo de Derechos Humanos, 2007, p. 12.
} 


\section{Proceso de desalojo en Chile}

En primer término no existe un registro o conteo de los procesos de desalojos, desahucios o lanzamientos ejecutados en Chile, por lo que no es posible tener un real acercamiento acerca de cuántas personas se ven afectadas diariamente por ellos.

Para comprender de mejor manera la situación es necesario realizar una distinción respecto de los desalojos de terrenos o inmuebles que pertenecen a privados, de aquellos que pertenecen al Estado, pues su tratamiento será distinto. Así, si hablamos de terrenos privados la única manera de obtener el desalojo en caso de ser ocupado de manera ilegal, sin tener título alguno sobre él, será por intermedio de los tribunales de justicia, quienes dictarán la orden judicial y solicitarán el auxilio de la fuerza pública en caso de ser necesario.

Al respecto es posible iniciar un juicio para hacer efectiva la hipoteca, interponer un recurso de protección para obtener el restablecimiento del derecho vulnerado, o bien alguna de las acciones reivindicatorias o posesorias establecidas en el Código Civil o también la acciones derivadas del contrato de arrendamiento. Una de las acciones más utilizadas para obtener la restitución de inmuebles que están siendo ocupados irregularmente y de esta manera solicitar desalojos en el ámbito judicial, corresponde al precario establecido en el artículo $2.195^{49}$ del Código Civil. En estos casos, existiendo resolución judicial ${ }^{50}$ que ordene el lanzamiento o desalojo, se puede recurrir al auxilio de la fuerza pública, y se debe practicar en la presencia del auxiliar de la administración de justicia denominado receptor judicial.

Para estos efectos no existe procedimiento reglado para proceder al desalojo, sin embargo dependerá del funcionario policial a cargo la observancia de determinadas conductas, lo que deja abierto a la arbitrariedad. Sin perjuicio de ello, el uso de la fuerza sí se encuentra regulada por la Circular No 176 de fecha 13 de marzo de 2013 que establece los principios de legalidad, necesidad y proporcionalidad en el uso de la misma, además de su uso diferenciado y gradual $^{51}$.

${ }^{49}$ Se entiende precario cuando no se presta la cosa para un servicio particular ni se fija tiempo para su restitución.

Constituye también precario la tenencia de una cosa ajena, sin previo contrato y por ignorancia o mera tolerancia del dueño. Artículo 2.195,Código Civil.

${ }^{50}$ Si no ha habido oposición al cumplimiento de la sentencia solicitado conforme al artículo 233 o ella ha sido desestimada por sentencia de primera o segunda instancia, se procederá a cumplirla, siempre que la ley no haya dispuesto otra forma especial, de acuerdo con las reglas siguientes:

$1^{\text {a }} \mathrm{Si}$ la sentencia ordena entregar una especie o cuerpo cierto, sea mueble o inmueble, se llevará a efecto la entrega, haciéndose uso de la fuerza pública si es necesario [....

De los juicios especiales del contrato de arrendamiento: Artículo 595: Si, ratificado el desahucio, llega el día señalado para la restitución sin que el arrendatario haya desalojado la finca arrendada, este será lanzado de ella a su costa, previa orden del tribunal notificada en la forma establecida por el artículo 48. Código de Procedimiento Civil, artículo 235.

${ }^{51}$ Circular $\mathrm{N}^{\mathrm{o}} 176$ de Carabineros de Chile, 2013. 
Pero tratándose de terrenos del Estado, sin perjuicio de tener las acciones señaladas anteriormente, la figura es diferente, pues mediante ley se le ha entregado la competencia para realizar desalojos, o en otras palabras, obtener la restitución del inmueble por la vía administrativa al Gobernador Provincial, o más bien actualmente al Delegado Presidencial Provincial. Este procedimiento se encontraba regulado mediante Oficio Circular $\mathrm{N}^{\circ} 19$ de 7 de marzo de 2017, emanado del Subsecretario del Interior, del Ministerio del Interior y Seguridad Pública, el que citaba entre sus fundamentos el Pacto Internacional de Derechos Económicos, Sociales y Culturales.

La referida circular contemplaba un procedimiento participativo de las familias que viven en los inmuebles a recuperar administrativamente, fijando plazos prudentes de notificación y velando por el principio de la información, asegurando la presencia de funcionarios del Estado que cautelaran la seguridad y la integridad de las personas, teniendo especial consideración a personas que se encontraban en situación de especial vulnerabilidad, como los niños, niñas y adolescentes, o adultos mayores, entre otras facultades.

Dicha circular fue dejada sin efecto por la Resolución Exenta No 2.137 de la misma Subsecretaría ya indicada, fundamentalmente porque adolecería de vicios de ilegalidad y atentaría contra el Estado de Derecho, restringiendo las facultades que la Ley No 20.502 le confería a dicha Subsecretaría, reconociéndose finalmente que en caso de presentarse situaciones urgentes, de tipo social o humanitaria, deberán emitirse los correspondientes actos administrativos que generen un procedimiento adecuado, a cuya conformación deberán concurrir todos los órganos implicados, velando por el resguardo del Estado de Derecho y el apego irrestricto a las normas constitucionales y legales vigentes ${ }^{52}$.

Lo ocurrido nos parece un retroceso en materia de respeto y promoción por los Derechos Humanos, por cuanto si bien concordamos en que la forma jurídica no era la adecuada, sí era y es necesario para la regulación de los procedimientos de desalojos administrativos que se cuenten con reglas claras, participativas y que no dejen en la indefensión a los pobladores de asentamientos irregulares, debiendo haberse dictado el acto administrativo correspondiente de manera paralela al acto que dejaba sin efecto la Circular $\mathrm{N}^{\circ} 19$ ya señalada.

\section{Normativa aplicable al Desalojo administrativo}

Tratándose de desalojos de inmuebles de dominio del Estado existen 3 normas centrales, el artículo $4^{\circ}$ literal h) de la Ley $\mathrm{N}^{\circ} 19.175$, Orgánica Constitucional sobre Gobierno y Administración Regional, el artículo 26 del Decreto con Fuerza de Ley N 22 de 1959, Orgánica del servicio de Gobierno Interior de la República, y el artículo 19 del

52 Resolución Exenta N 2.137 de 25 de abril de 2018, obtenida por medio del procedimiento establecido por la Ley de acceso a la información pública, $\mathrm{N}^{\mathrm{o}} 20.285$. 
Decreto Ley $\mathrm{N}^{\circ} 1.939$ de 1977, que dispone normas sobre adquisición, administración y disposición de bienes del Estado.

La Ley $\mathrm{N}^{\circ} 19.175$ establece en su artículo $3^{\circ}$ que en cada provincia existirá una Delegación Presidencial Provincial, cargo creado por la Ley $\mathrm{N}^{\circ} 21.073$ de 2018, los que según las disposiciones transitorias de esta última ley y la Ley $\mathrm{N}^{\circ} 21.074$, mientras no asuman los gobernadores regionales electos, ejercerán estos primeros sus funciones y atribuciones $^{53}$. Por su parte el artículo $4^{\circ}$ señala respecto de las atribuciones del Delegado Presidencial Provincial, que podrá realizar lo siguiente:

“h) Ejercer la vigilancia de los bienes del Estado, especialmente de los nacionales de uso público.

En uso de esta facultad, el delegado presidencial provincial velará por el respeto al uso a que están destinados, impedirá su ocupación ilegal o todo empleo ilegítimo que entrabe su uso común y exigirá administrativamente su restitución cuando proceda”.

En cuanto al Decreto con Fuerza de Ley N 22 de 1959, su artículo 26 dispone que el Gobernador

“Tendrá las siguientes atribuciones:

f) Exigir administrativamente la restitución de cualquier bien de propiedad fiscal o perteneciente a entidades del Estado con patrimonio distinto al del Fisco, o nacional de uso público, que esté indebidamente ocupado. En caso de oposición, podrá hacer uso de las facultades que le otorga la presente ley.

Si el ocupante exhibe un título aparente de ocupación o de mera tenencia, enviará los antecedentes al Consejo de Defensa del Estado para su pronunciamiento, dando cuenta a los Ministerios del Interior y Seguridad Pública y de Tierras y Colonización. En el intertanto, se abstendrá de actuar.

Los Conservadores de Bienes Raíces estarán obligados a comunicar al Gobernador las inscripciones de propiedades de particulares que no tengan título anterior inscrito".

${ }^{53}$ Ley $\mathrm{N}^{\circ} 21.073$, Artículo $1^{\circ}$ inciso $5^{\circ}$ transitorio: Las disposiciones contenidas en los numerales 20; 24; 25; 28, letra d); 29; 32; 33; 35; 39, y 40 del artículo 1 de esta ley, así como los artículos 5, 6, 7 y 8 entrarán en vigencia una vez que asuman los primeros gobernadores electos. Mientras no asuman los gobernadores regionales electos, ejercerán sus funciones y atribuciones los delegados presidenciales regionales, con excepción de las funciones del presidente del consejo regional. Asimismo, mientras no asuman dichas autoridades, las disposiciones que establece la ley referida a los delegados presidenciales regionales y a los delegados presidenciales provinciales serán aplicables a los intendentes y gobernadores, respectivamente.

Ley N²1.074 Artículo séptimo: Mientras no asuman los gobernadores regionales electos, las normas legales de la presente ley que hagan referencia a dichas autoridades se entenderán referidas al intendente, en su calidad de órgano ejecutivo de los gobiernos regionales; y las que hacen referencia al delegado presidencial regional, al intendente como representante del Presidente de la República. www.bcn.cl 
Finalmente el Decreto Ley $\mathrm{N}^{\circ} 1.939$ de 1977 en su artículo 19 mandata que

"La Dirección [de Tierras y Bienes Nacionales], sin perjuicio de las facultades que le competen a los Intendentes Regionales y Gobernadores Provinciales, cuidará que los bienes fiscales y nacionales de uso público se respeten y conserven para el fin a que estén destinados. Impedirá que se ocupe todo o parte de ellos y que se realicen obras que hagan imposible o dificulten el uso común, en su caso.

Los bienes raíces del Estado no podrán ser ocupados si no mediare una autorización, concesión o contrato originado en conformidad a esta ley o de otras disposiciones legales especiales.

Todo ocupante de bienes raíces fiscales que no acreditare, a requerimiento de la Dirección, poseer alguna de las calidades indicadas en el inciso anterior, será reputado ocupante ilegal, contra el cual se podrán ejercer las acciones posesorias establecidas en el Título IV del Libro III del Código de Procedimiento Civil, sin que rija para el Fisco lo establecido en el número 1 del artículo 551, del citado Código”.

Las normas recientemente citadas fundan los actos administrativos que ordenan proceder a la restitución administrativa de los terrenos ocupados ilegalmente, y que sirve de base para el desalojo, dictados por las Gobernaciones Provinciales, en especial las contenidas en los artículo 4 letra h) de la Ley $\mathrm{N}^{\circ} 19.175$, y el artículo 26 del Decreto con Fuerza de Ley No 22 de 1959. Ello resulta de importancia, por cuanto se ha discutido en tribunales a propósito de determinados recursos de protección interpuestos por grupos de pobladores de asentamientos irregulares, acerca de la procedencia de la aplicación de la restitución administrativa, si esta es legal o si existe una derogación tácita de algunas normas por sobre otras. Seguir una u otra postura, sostener la derogación o que la actuación se encuentra dentro del marco legal, marcará la diferencia entre lograr la paralización de un procedimiento de desalojo administrativo basándose solo en la normativa legal vigente.

A modo de ejemplo, en causa Rol 118-2017 seguida ante la Corte de Apelaciones de Arica, pobladores de la población Cerro Chuño interpusieron un recurso de protección a objeto de impedir se cumpliera con la orden de desalojo producto de la restitución administrativa que perseguía la Gobernación Regional respecto de un terreno de dominio del Servicio de Vivienda y Urbanización de la Región de Arica y Parinacota. Al respecto el tribunal sustentó una tesis que puede parecer a lo menos discutible pero útil para detener que se llevara a cabo el proceso administrativo, esto es, que la facultad entregada al gobernador en virtud del artículo $4^{\circ}$ letra $\mathrm{h}$ ), solo se puede hacer efectiva respecto de bienes nacionales de uso público y que tiene importancia, pues el inmueble ocupado irregularmente no tenía dicho carácter; para ello indica cuatro motivos principales ${ }^{54}$ :

${ }^{54}$ Corte de Apelaciones de Arica. 10.03.2017, rol 118-2017. 
- Una interpretación literal de la norma contenida en la letra h) del artículo $4^{\circ}$ de la Ley $N^{\circ} 19.175$, según este, la atribución del Gobernador Provincial para efectos de decretar el desalojo dice relación con bienes que poseen el carácter de nacional de uso público, debido a que circunscribe su atribución especialmente a aquellos que poseen el carácter de bien nacional de uso público.

- Una interpretación lógica, ya que "del propio tenor del artículo $4^{\circ}$ de la Ley $\mathrm{N}^{0}$ 19.175, aparece que las atribuciones del Gobernador Provincial dicen relación con bienes nacionales de uso público, verbi gracia, la letra c) referente a la autorización de reuniones en plazas, calles y demás lugares de uso público”.

- Una interpretación sistémica, en donde "las atribuciones de conservación de los bienes nacionales de uso público, radicadas en el Gobernador Provincial, igualmente aparecen reflejadas en tal sentido en otros cuerpos normativos, otorgándoles facultades para ordenar su restitución administrativa".

- Finalmente una interpretación histórica, ya que se basa en el mensaje con el que fue enviado el proyecto de ley que buscaba la modificación del artículo 19 del D.L. N ${ }^{\circ} 1.939$, al Congreso Nacional”.

Por otro lado, la Corte de Apelaciones de Arica deduce que la aplicación del artículo 26 del Decreto con Fuerza de Ley No 22 no corresponde por cuanto fue derogada tácitamente por la norma establecida en el artículo $4^{\circ}$ letra h) de la Ley $\mathrm{N}^{\circ} 19.175$.

De esta manera, sosteniendo el argumento recientemente expuesto, la Corte resuelve en lo que nos importa, que el actuar del Gobernador Provincial de Arica resulta ilegal, atendiendo a la naturaleza jurídica del inmueble objeto de la restitución, que en este caso corresponde a un bien fiscal que no tiene el carácter de bien nacional de uso público, siendo por tanto procedente la aplicación de la norma del artículo 19 del Decreto Ley $\mathrm{N}^{\circ} 1.939$ de 1976 y no el artículo $4^{\circ}$ letra h) de la Ley $\mathrm{N}^{\circ} 19.175$, señalando además que su obrar ilegal se basaba en haber fundado su actuar en el artículo 26 letra f) del Decreto con Fuerza de Ley $\mathrm{N}^{\circ} 22$, de 1959, el que se encuentra derogado tácitamente. Lo anterior se encuentra firme y ejecutoriado al haberse interpuesto recurso en su contra, y haberse confirmado por la Corte Suprema ${ }^{55}$.

A este respecto, llama la atención que no se haya hecho referencia alguna al derecho a la vivienda adecuada relacionándolo con el derecho a la vida que sí tiene consagración constitucional, y que como ya se ha indicado por la relatora especial para la vivienda adecuada Leilani Farha ${ }^{56}$, está íntimamente relacionado con el primero en tanto la violación de uno trae aparejado la vulneración del otro, y que el derecho a la vivienda adecuada forma parte del derecho a un nivel de vida adecuado.

Sin perjuicio de haberse logrado detener un proceso de desalojo fundado en las motivaciones indicadas, en nuestro país impera el principio del efecto relativo de las sentencias establecido en el artículo $3^{\circ}$ del Código Civil, a causa de ello "Las sentencias

\footnotetext{
55 Corte Suprema, 26.10.2017, rol 10.203-2017.

56 Consejo de derechos humanos, 2016.
} 
judiciales no tienen fuerza obligatoria sino respecto de las causas en que actualmente se pronunciaren ${ }^{57}$ ". Debido a ello es posible encontrar tribunales con criterios distintos al ya referido, como sucedió en la causa Rol 174-2018 de la Corte de Apelaciones de Antofagasta, quien conoció por la vía del recurso de protección interpuesto por pobladores de los campamentos Américas Unidas, Unión y Esperanza y Ecuachilep de la ciudad de Antofagasta, quienes se dirigían en contra de la orden de desalojo dictada por la Gobernadora Provincial de Antofagasta.

En la sentencia dictada el 27 de febrero de 2018 a propósito de la diferencia entre los bienes nacionales de uso público y el resto de los bienes fiscales en el artículo $4^{\circ}$ letra h) de la Ley $\mathrm{N}^{\circ} 19.175$, la Corte señala que en dicha norma "precisamente por la definición legal no puede el intérprete pretender que cuando la norma habla de todo empleo ilegítimo que entrabe su uso común se esté refiriendo exclusivamente a los bienes nacionales de uso público" 58 .

Por otro lado, en cuanto a la aplicación del artículo 19 del D.L. N 1.939 la Corte indica que la facultad en dicha norma contenida es "sin perjuicio de las facultades que le competen a los Intendentes Regionales y Gobernadores Provinciales"59.

En cuanto al argumento de la derogación tácita del artículo 26 del D.F.L. 22 de 1959 se indicó que:

"No es efectivo que el Decreto Ley No 1.439 de 1976 derogara tácitamente la normativa señalada en el párrafo anterior, pues se limitó a indicar, en el contexto del proceso de regionalización que entregara (sic) en vigencia ese mismo año, que las atribuciones y deberes que la legislación vigente señala para los Intendentes provinciales y Gobernadores departamentales, mientras no se dictaren normas definitivas en la materia, lo que no puede predicarse, en términos absolutos con pretensión de exclusión de cualquier otro texto normativo, ocurriera con la dictación de la Ley N 19.175 , Orgánica Constitucional sobre Gobierno y Administración Regional.

Dicha sentencia se encuentra firme al haber sido confirmada por la Corte Suprema. Es posible observar que lo referido es una situación que actualmente es objeto de discusión, pero para nosotros parece clara que la facultad entregada por la Ley $\mathrm{N}^{\circ} 19.175$ se puede ejercer respecto de todo tipo de inmuebles que sean de propiedad del Estado, no tan solo de los bienes nacionales de uso público. Sí aparece de manifiesto que resultaba necesario haber hecho referencia en las sentencias a la obligación de proceder con pleno respeto de la dignidad humana en los procesos de desalojos, más en los casos mencionados las Cortes decidieron referirse solo a la aplicación de la normativa citada, y no pronunciarse respecto del fondo del asunto.

\footnotetext{
57 Código Civil, 1857.

58 Corte de Apelaciones de Antofagasta, 27.02.2018, rol 174-2018.

59 Corte de Apelaciones de Antofagasta, 27.02.2018, rol 174-2018.
} 
Por último mencionar que la Ley $\mathrm{N}^{0} 17.635$ que establece normas sobre cobro ejecutivo de créditos por parte de los Servicios de Vivienda y Urbanización o SERVIU, fija un procedimiento especial ante los tribunales de justicia para obtener el pago de los créditos insolutos, e incluso para rematar viviendas en caso de incumplimiento de la obligación de habitar que pesa sobre los beneficiarios del subsidio habitacional. En estos casos, se ordena el embargo y se procede el remate de la vivienda, pudiendo adjudicarse en dominio al SERVIU respectivo, quien podrá reasignarla a otra familia con urgente necesidad habitacional. Igualmente, para obtener el desalojo se debe contar con el auxilio de la fuerza pública.

Esta última norma afecta directamente a la población más vulnerable del país, quien por ley se encuentra obligada a habitar personalmente y/o su grupo familiar la vivienda financiada con subsidio habitacional, permitiéndoles solo en casos fundados excepcionar su cumplimiento por parte de la administración pública.

\section{CONCLusiones}

Como primer asunto preocupante aparece la falta de regulación y control que existe respecto del actuar de las autoridades de orden y seguridad para proceder a los desalojos cuando estos son requeridos por orden judicial o por orden administrativa. Al no existir un marco legal específico, queda a la arbitrariedad de quien está a cargo del proceso el horario en que se realizará, si se comunica con otras entidades, y si cautela en especial los derechos de personas en situación de vulnerabilidad, entre otros asuntos. Lo anterior nos lleva a concluir que es posible que, tanto en los desalojos de terrenos privados como públicos, se incumplan con los estándares internacionales y se constituyan como forzosos, afectando la dignidad de las personas que son objeto de ellos.

Es de público conocimiento que en algunos de estos procedimientos de desalojos ${ }^{60}$, incluso en los de terrenos de dominio público, se hacía (o hace) uso desmedido de la fuerza en contra de personas indefensas, lo que ha sido visibilizado por la prensa nacional. Y en general, dichos desalojos ocurren respecto de personas en situación de vulnerabilidad económica, con baja escolaridad, y pocas posibilidades de defenderse o ejercer alguna acción en su protección.

Constituía un avance en esta materia la dictación de la Circular $\mathrm{N}^{\circ} 19$ de 7 de marzo de 2017 de la Subsecretaría del Interior, al pretender hacer aplicable a los procedimientos de desalojos administrativos llevados adelante por la Gobernación Regional, reglas que tuvieran en el centro la dignidad de las personas, haciéndolas partícipes del proceso, y cautelando su integridad, incluso al otorgar soluciones habitacionales transitorias. Lamentamos que el Ministerio del Interior haya decidido dejarla sin efecto, perdiendo de esta manera la oportunidad de guiar su actuar de conformidad con los estándares

${ }^{60}$ Revisar entre otras noticias, http://www.eldesconcierto.cl/2016/11/10/brutal-desalojo-en-campamentode-colina-la-vulneracion-al-derecho-a-la-vivienda-y-a-la-no-discriminacion-en-chile/; http://impresa.lasegunda. com/2016/08/11/A/FN301252/D83014GU 
internacionales, lo que no obsta para que en un futuro se dicte un nuevo procedimiento, de conformidad a lo establecido en la propia Resolución Exenta $\mathrm{N}^{\mathrm{o}} 2.137$ de 25 de abril de 2018.

Añadir que los estándares internacionales son claros y específicos, y han sido establecidos para servir de guía a los Estados que han ratificado el Pacto, y que no hacen más que cautelar el respeto por los derechos y la dignidad humana. A raíz de lo anterior, Chile no puede abstraerse de su cumplimiento y, por tanto, urge una regulación a nivel legal respecto del procedimiento de desalojo, en orden a cumplir y respetar el derecho internacional de los derechos humanos.

Aparece como de gran importancia señalar que es necesario el reconocimiento constitucional del derecho a la vivienda adecuada, entre otros derechos económicos, sociales y culturales, y que este tenga la debida protección jurisdiccional, haciendo caso de la recomendación efectuada por el Comité respecto del informe de Chile en el $2015^{61}$.

Al respecto una posibilidad para otorgar seguridad jurídica de la tenencia una vez producido el desalojo, podría encontrarse en la facultad entregada por vía glosa de ley de presupuesto al Ministerio de Vivienda y Urbanismo, de financiar la adquisición de terrenos a organizaciones que no persiguen fines de lucro para que las entreguen en arriendo a beneficiarios del Decreto Supremo No 52 que establece el programa de arriendo $^{62}$. Si se actúa interministerialmente por medio del Departamento de Asentamientos Precarios $^{63}$ del Ministerio de Vivienda y Urbanismo quienes son los encargados de proponer la política habitacional para la atención de los asentamientos indicados; y coordinadamente con estas fundaciones u organizaciones sin fines de lucro, es posible entregar una solución al menos transitoria a las personas, que les facilite un lugar para vivir en dignidad, paz y seguridad.

Finalmente señalar que la relevancia de los criterios jurisprudenciales indicados en este trabajo harán la diferencia en cuanto permitir la paralización de un proceso de desalojo, unidos estos argumentos a los mencionados tratándose de los estándares internacionales tanto en materia de desalojo forzoso como el derecho a la vivienda adecuada. De esta

61 Comité de Derechos Económicos, Sociales y Culturales, 2015.

62 Glosa 3, letra i), asociada a subtítulo 33, ítem 01 de la ley de presupuestos para el sector público año 2018, Ley No 21.053. Disponible en www.bcn.cl o http://www.dipres.gob.cl/597/w3multipropertyvalues-15199-24043.html

El Ministerio de Vivienda y Urbanismo, mediante los Servicios de Vivienda y Urbanización, podrá otorgar subsidios de los Programas Habitacionales vigentes, a personas jurídicas de derecho público o privado sin fines de lucro que tengan por objeto construir viviendas o transformarlas en residencias multifamiliares o mejorarlas, las que serán destinadas en todos los casos al arrendamiento a familias que cumplan con los requisitos del Programa regulado por el D.S. 52, (V. y U.), de 2013.

El otorgamiento de los referidos subsidios, los gravámenes y sus plazos asociados a las edificaciones y las condiciones de los llamados se regularán por resolución exenta del Ministro de Vivienda y Urbanismo, visada por la Dirección de Presupuestos del Ministerio de Hacienda, la que podrá dictarse una vez publicada la Ley de Presupuestos del Sector Público para el 2018.

63 Decreto $\mathrm{N}^{\circ} 15$ de 18 de abril de 2017 del Ministerio de Vivienda y Urbanismo, que establece estructura orgánica y funciones de unidades de la división de desarrollo urbano y de la división de política habitacional, en la subsecretaría de vivienda y urbanismo. Disponible en www.bcn.cl 
manera aludir a los compromisos internacionales asumidos por el Estado de Chile en virtud de la ratificación del Pacto, permitirá causar un pronunciamiento adecuado por parte de los tribunales superiores de justicia respecto de la pertinencia del procedimiento de desalojo llevado a cabo, y cuestionar de esta manera el actuar de la administración, ya sea que proceda a un desalojo de terreno privado o público.

\section{BIBLIOGRAFÍA}

Augusto, Isaac, El derecho a la vivienda en Argentina. Disponible en https://archivos.juridicas. unam.mx/www/bjv/libros/7/3052/12.pdf

Bertelsen, Raúl, Rango jurídico de los tratados internacionales en el derecho chileno, en Revista Chilena de Derecho, Vol. 23, No 2 y 3, Tomo I, pp. 211-222, 1996. Disponible en https:// repositorio.uc.cl/bitstream/handle/11534/14645/000179000.pdf? sequence $=1$

Candia, Gonzalo, Introducción al Derecho Internacional de los Derechos Humanos. Análisis, doctrina y jurisprudencia. 2016.

CirCular No 176 de 13 de marzo de 2013, http://deptoddhh.carabineros.cl/assets/circular_ digcar_1756_13032013_usodelafuerza.pdf

Código Civil, publicado con fecha 14 de diciembre de 1855.

Código de Procedimiento Civil, publicado con fecha 30 de agosto de 1902.

Comité de Derechos Económicos Sociales y Culturales. Observación General № 7 . Los desalojos forzosos. E/1998/22. 1997. Disponible en http://hrlibrary.umn.edu/gencomm/ epcomm7s.htm [Fecha de consulta: 05.02.2018].

Comité de Derechos Económicos, Sociales y Culturales. Comunicación 2/2014, 13 de octubre de 2015. Disponible en http://juris.ohchr.org/Search/Results [Fecha de consulta 27 de marzo de 2018].

Comité de Derechos Económicos, Sociales y Culturales. Observaciones finales sobre el cuarto informe periódico de Chile, punto 7, 2015. Disponible en http://acnudh.org/24619/ [Fecha de consulta: 16 de marzo de 2018].

Comité de Derechos Económicos, Sociales y Culturales. Observación General № 4, $6^{\circ}$ período de sesiones, 13 de diciembre de 1991. [Fecha de consulta: 05.02.2018].

Comité de Derechos Humanos, Comunicación 2073/2011, 27 de noviembre de 2012. Disponible en http://undocs.org/es/CCPR/C/106/D/2073/2011 [Fecha de consulta: 6 de marzo de 2018].

Consejo de Derechos Humanos, ONU. Informe de la Relatora Especial para la Vivienda Adecuada, La vivienda adecuada como elemento integrante del derecho a un nivel de vida adecuado, Leilani Farha, A/71/310. 2016. Disponible en http://ap.ohchr.org/documents/ dpage_s.aspx?s=35 [Fecha de consulta: 02.02.2018].

Consejo de Derechos Humanos, ONU. "Principios básicos y directrices sobre los desalojos y el desplazamiento generados por el desarrollo", anexo I del Informe del Relator Especial sobre una vivienda adecuada, como parte del derecho a un nivel de vida adecuado. A/HRC/4/18, 2007. Disponible en: http://www.ohchr.org/Documents/Issues/Housing/Guidelines_sp.pdf [Fecha de Consulta: 06.02.2018].

Consejo de Derechos Humanos, ONU. Informe de la Relatora Especial sobre una vivienda adecuada como elemento integrante del derecho a un nivel de vida adecuado, Raquel Rolnik. A/67/286. 2012. Disponible en http://www.ohchr.org/Documents/Issues/Housing/A-67-286_ sp.pdf [Fecha de consulta: 12 de febrero de 2018]. 
Convención Americana sobre Derechos Humanos. Adoptada el 22 de noviembre de 1969. Publicada en Chile con fecha 5 de enero de 1991.

Corte de Apelaciones de Antofagasta, sentencia de fecha 27 de febrero de 2018, rol 174-2018. Corte de Apelaciones de Arica, Sentencia de fecha 10 de marzo de 2017, rol 118-2017.

Corte Europea de Derechos Humanos. Caso "Connors versus Reino Unido", 27 de mayo de 2004. Disponible en inglés en https://www.echr.coe.int/Pages/home.aspx?p=caselaw\&c =\#n14597620384884950241259_pointer

D'Aspremont, Jean, Formalism and the sources of international law: a theory of the ascertainment of legal rules. 2011, en Candia, Gonzalo, Introducción al Derecho Internacional de los Derechos Humanos. Análisis, doctrina y jurisprudencia. 2016.

De los Ríos, Silvia. El Derecho a la vivienda y las declaraciones constitucionales en Revista INVI $\mathrm{N}^{\circ}$ 62, volumen 23, mayo 2008. Disponible en http://revistainvi.uchile.cl/index. $\mathrm{php} / \mathrm{INVI} / \mathrm{article} / \mathrm{view} / 422$

Del Toro, M., El fenómeno del soft law y las nuevas perspectivas del derecho internacional, en anuario mexicano de derecho internacional, 2006, vol. VI; en Feler, Alan, Soft Law como herramienta de adecuación del derecho internacional a las nuevas coyunturas, 2015. Disponible en http://www.derecho.uba.ar/publicaciones/lye/revistas/95/soft-law-comoherramienta-de-adecuacion-del-derecho-internacional-a-las-nuevas-coyunturas.pdf

Diccionario de la Real Academia Española, vigésima primera edición, Madrid, 1992, Espasa-Calpe.

Diccionario de la Real Academia Española. Disponible en www.rae.es [Fecha de consulta: 18.03.2018].

Etimologías de Chile, 2018. Recuperado el 20.03.2018: www.etimologias.dechile.net

Fundación TECHO-CHILE, Centro de Investigación Social (CIS), Monitor de Campamentos. Disponible en línea http://chile.techo.org/cis/monitor/ [Fecha de consulta: 18.03.2018].

Habitat Worldmap, palabras claves. 2017. Recuperado el 05.03.2018 del sitio web de la organización: http://habitat-worldmap.org/es/palabras-clave/asentamientos-informales/

INDH, Informe Anual 2012, situación de los derechos humanos en Chile, 2012. Disponible en http://bibliotecadigital.indh.cl/bitstream/handle/123456789/296/informe-anual-2012. pdf? sequence $=1$

LEY N ${ }^{\circ}$ 19.175, Publicado con fecha 11 de noviembre de 1992.

NASH, Claudio, Derecho Internacional de los Derechos Humanos en Chile. Recepción y aplicación en el ámbito interno. 2012. Disponible en http://www.libros.uchile.cl/371

Nash F., Paredes G. 2011, Análisis crítico de las políticas de vivienda social en chile, fundamentos para el reconocimiento del derecho a la vivienda. Memoria para optar al grado de Licenciado en Ciencias Jurídicas y Sociales, Universidad de Chile. Disponible en http:// repositorio.uchile.cl/bitstream/handle/2250/111577/deNash_Fernanda.pdf? sequence $=3$

Nogueira, Humberto, 2009, Los derechos económicos, sociales y culturales como derechos fundamentales efectivos en el constitucionalismo democrático latinoamericano, en Estudios Constitucionales, año 7, $\mathrm{N}^{\circ}$ 2, 2009. Disponible en https://scielo.conicyt.cl/scielo. php? script $=$ sci_arttext $\&$ pid $=$ S0718-52002009000200007

Olano, Hernán, 2006, El derecho a la vivienda digna en Colombia. Disponible en http://dikaion. unisabana.edu.co/index.php/dikaion/article/view/1349

Oficina del Alto Comisionado de Derechos Humanos, ONU, 2014, Folleto informativo $\mathrm{N}^{\circ} 25$ Los Desalojos Forzosos y los Derechos Humanos. Disponible en http://www.ohchr. org/Documents/Publications/FactSheet25sp.pdf [Fecha de consulta: 03.02.2018].

Oficio Circular N ${ }^{\circ} 19$ de 07 de marzo de 2017, del subsecretario del interior, ministerio del interior y seguridad pública, gobierno de Chile. Disponible en http://www.techo.org/paises/ 
chile/informate/interior-aprueba-protocolo-de-desalojo-impulsado-por-techo-chile/ [Fecha de consulta: 05.02.2018].

ONU, Definición de relator especial http://www.lan.ohchr.org/SP/Issues/Housing/Pages/ HousingIndex.aspx 20.03.2018

Pacto Internacional de Derechos Civiles y Políticos, adoptado el 16 de diciembre de 1966. Publicado en Chile con fecha 29 de abril de 1989.

Pacto Internacional de Derechos Económicos, Sociales y Culturales. Adoptado el 16 de diciembre de 1966. Publicado en Chile con fecha 27 de mayo de 1989.

Resolución Exenta N 2.137 de 25 de abril de 2018, de la subsecretaría del interior, del Ministerio del Interior, obtenida a través de la ley de acceso a la información pública, $\mathrm{N}^{\circ} 20.285$.

Subcomisión de Promoción y Protección de los Derechos Humanos, Resolución $N^{\circ}$ 2003/17. Disponible en http://www.acnur.org/t3/fileadmin/Documentos/BDL/2005/3246. pdf? view $=1$ [Fecha de consulta: 15.03.2018]. 